\title{
Immunology at Duke: 2011
}

\author{
Michael S. Krangel
}

Published online: 30 November 2010

(C) Springer Science+Business Media, LLC 2010

The rich tradition and long history of immunology at Duke University Medical Center were elegantly described by Drs. Francis Ward and Thomas Tedder in their introductory remarks to the first edition of Immunology at Duke which appeared in this journal 11 years ago [1]. The central figure in this story was the colorful Dr. D. Bernard Amos, who founded and led the Division of Immunology for nearly 30 years until his retirement in 1990. Leadership of the Division briefly passed to Dr. Peter Cresswell; his departure to Yale in 1991 then served as the catalyst for the creation of a separate Department of Immunology. Dr. Jeffrey Dawson served as Interim Chairman of the new department until Dr. Thomas Tedder was recruited as Chair in 1993. Dr. Tedder served admirably in that capacity for 16 years, recruiting almost the entire current faculty and building the Department into what it is today. Dr. Tedder stepped down in 2009, passing the leadership to Dr. Michael Krangel, initially on an interim basis. Dr. Krangel was appointed Chair in 2010.

The Department of Immunology developed in important ways over the last decade with the addition of new primary and secondary faculty members and a major expansion of the graduate program. Today the Department serves as the focal point for research and education in immunology at Duke. The departmental structure provides a tremendous advantage in that immunology has a physical home that facilitates cohesiveness and interactions among faculty, students, postdoctoral fellows, and staff. The Department consists of 15 primary faculty and 30 secondary faculty, with secondary faculty members drawn from a range of departments: Biostatistics and Bioinformatics, Dermatology, Medicine, Molecular Genetics and Microbiology, Opthalmology, Pathology, Pediatrics, Pharmacology and Cancer Biology, and Surgery. The breadth of secondary appointments speaks to the interdisciplinary nature of the immunology community at Duke. This is of course a major strength of the program; collaborative interactions between basic and clinical scientists enrich both the research and educational activities of the Department.

The articles in this volume provide a sampling of the research activities of basic and clinical immunologists at Duke. Contributions on the basic research side address the regulation and function of the activation-induced cytidine deaminase in B lymphocytes

M. S. Krangel ( $)$

Department of Immunology, Duke University Medical Center, Durham, NC, USA

e-mail: krang001@mc.duke.edu 
(Drs. Kelsoe and Unniraman), the regulation of T-cell development by E2A transcription factors (Dr. Zhuang), the regulation of T-cell receptor gene assembly (Dr. Krangel), signal transduction pathways important for the development and functioning of immune cells (Drs. Zhang and Zhong), the roles of apoptotic and autophagic pathways in T-lymphocyte development and function (Dr. He), the role of signaling pathways in hematopoiesis and hematopoietic malignancies (Dr. Kondo), microRNA control of T-cell differentiation and function (Dr. Li), the role of osteopontin in innate and adaptive immune responses (Dr. Shinohara), the function of regulatory $\mathrm{T}$ cells during acute and chronic infections (Dr. Yang), and B-cell effector mechanisms (Dr. Tedder). Clinical research contributions describe hematopoietic stem cell transplantation for primary immunodeficiency diseases (Drs. Buckley and Sarzotti-Kelsoe), novel therapies for food allergies (Dr. Burks), the development of cancer vaccines (Drs. Clay and Lyerly), cellular and humoral immune responses to HIV (Drs. Tomaras and Frank), B-cell lymphoproliferative disorders (Dr. Weinberg), DNA autoantigens in SLE (Dr. Pisetsky), allogeneic hematopoietic cell transplantation (Dr. Szabolcs and Chao), and innate immunity in the lung (Dr. Hollingsworth).

Looking to the future, the Department of Immunology will continue to grow and broaden its research and educational enterprises, will continue to build bridges between basic and clinical scientists, and will continue to provide new fundamental insights into the development and functioning of the immune system and into pathologies such as immunodeficiency, autoimmunity, infectious disease, and cancer.

Sadly, both Dr. Amos and one of his earliest recruits, Dr. Richard Metzgar, have passed away since the Department was last featured in these pages. The present-day Department of Immunology owes everything to these pioneers. The Department dedicates this volume to their memory.

More information about the Department of Immunology can be found on our Web site http://immunology.mc.duke.edu.

\section{Reference}

1. Ward FE, Tedder TF. Immunology at duke. Immunol Res. 2000;22:67-9. 